\title{
Characteristics of Sexual Behavior in Blind Males: a Cross-sectional Survey
}

\section{Shaoming Huang}

Ganzhou Municipal Hospital

\section{Shenghuang Zhu}

Ganzhou Municipal Hospital

\section{Renfu Liu}

Ganzhou Municipal Hospital

\section{Chuanchuan Xiong}

Ganzhou Municipal Hospital

\section{Lixin Liu}

The people's hospital of Yudu county

\section{Shuangshuang Li}

Ganzhou Municipal Hospital

\section{Shihan Liu}

Ganzhou Municipal Hospital

\section{Yuan Shu}

Ganzhou Municipal Hospital

Biao Qian ( $\nabla$ qianbiao@gmu.edu.cn )

The First Affiliated Hospital of Gannan Medical College

Jiaguo Huang

Affiliated Xiaoshan Hospital, Hangzhou Normal University

\section{Research Article}

Keywords: Sexual arousal, blind males, sexual behavior, cross-sectional survey, arousal

Posted Date: September 15th, 2021

DOl: https://doi.org/10.21203/rs.3.rs-882722/v1

License: (c) (1) This work is licensed under a Creative Commons Attribution 4.0 International License. Read Full License 


\section{Abstract}

Objective: To investigate access to sexual knowledge, understanding of the sexual partners' beauty and sexual arousal in blind males and analyze the factors affecting them.

Methods: A total of 54 blind males were conducted a face-to-face interview survey and questionnaire by the trained investigators.

Results: The sound of mobile phones accounted for $51.9 \%$ of access to sexual knowledge, radio for $27.8 \%$, the sound of television for $35.2 \%$, and peer communication for $48.1 \%$. The gentle and pleasant voice $(64.8 \%)$ was most frequent on understanding of the sexual partners' beauty, followed by sexy and stylish figure (55.5\%), fine and smooth skin (51.9\%) and attractive body fragrance (18.5\%). The results on the stimulation of sexual arousal showed that hearing gentle and pleasant sounds accounted for $40.7 \%$, touching delicate and smooth skin for $44.4 \%$, touching sexy and stylish figure for $53.7 \%$, and pleasant mood for $22.2 \%$.

Conclusion: Blind males lack formal and systematic sex education in Ganzhou. And the understanding of the sexual partners' beauty mainly includes hearing, touch and smell. The stimulation of sexual arousal is mainly reflected in sound and touch, and pleasant mood also has a certain impact.

\section{Introduction}

Sexual arousal includes subjective arousal and physiological arousal. Subjective arousal is the emotional experience of sexual arousal, including the awareness of self arousal, expected feedback and stimulated desire. Physiological arousal is caused by vasodilation of genital tissue. Sexual arousal depends on neural factors such as sensory and cognition, hormonal factors and genetic factors. In the case of human beings, it also depends on the complex influence of culture and environment. Sexual arousal is a dynamic and highly coordinated neurophysiological process, which is usually caused by visual stimulation ${ }^{1}$. Visual organ is the most important sensory organ of human beings. About $80 \% \sim 90 \%$ of the information received by the human body from the external environment is input from the visual channel. Because of the damage or lack of vision, it must have an impact on cognition, motivation, emotion and autonomous response. In order to understand the current situation of the stimulation of blind males' sexual arousal, the understanding of the sexual partners' beauty and access to sexual knowledge, provide more blind related data for the research of andrology diseases, and help to improve the quality of blind males' sexual life, this survey is carried out.

\section{Materials And Methods}

Object of Studies

This was a cross-sectional study with a convenience sample. In China, individuals diagnosed with visual impairment by a medical doctor are registered in the disabled persons' federations and blind 
associations. According to the visual disability standard of the second sampling survey of the disabled in China, the visual disability is divided into four levels. Individuals who have a best-corrected visual acuity of $₫ 0.02$ or visual field radius $\varangle 5^{\circ}$ in the better-seeing eye are classified as grade 1 , those with bestcorrected visual acuity of $0.02 \varangle \square .05$ or visual field radius $\triangle 10^{\circ}$ in the better-seeing eye as grade 2 , those with best-corrected visual acuity of $0.05 \mathrm{~B} 0.1$ in the better-seeing eye as grade 3 , those with best-corrected visual acuity of $0.1 \mathrm{Q} 0.3$ in the better-seeing eye as grade 4 . If both eyes have different vision, the one with better vision shall prevail. The best corrected vision refers to the best vision that can be achieved by correcting with appropriate lenses, or the vision measured by pinhole mirror. Those with visual field radius less than $10^{\circ}$ are blind regardless of their visual acuity ${ }^{2,3}$.

\section{Survey Questionnaire}

The survey questionnaire is designed according to the principles of purpose, acceptability, order, conciseness and matching. On the basis of fully demonstrating the reliability and validity of the survey and after the review by the Ethics Committee of Ganzhou Municipal Hospital, the contents of the formal questionnaire are optimized into general conditions such as name, age, marital status, etc., access to sexual knowledge, understanding of the sexual partners' beauty, stimulation of sexual arousal.

Inclusion Criteria

$\varangle$ Adult male over 18 years old; $\otimes$ Individuals with visual disability rated as grade 1 and grade 2 vision by relevant professional departments; $₫$ Voluntary respondents.

\section{Exclusion Criteria}

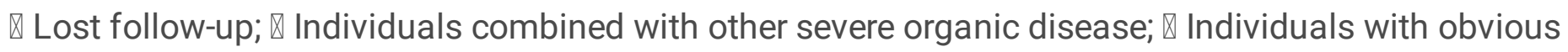
genital deformity.

Investigation Methods

This study was approved by the Ethics Committee of Ganzhou Municipal Hospital, all methods were carried out in accordance with relevant guidelines and regulations. This study was carried out in compliance with the Declaration of Helsinki. According to the roster provided by the Disabled Persons' federations and blind associations in Ganzhou, the blind males who meet the inclusion criteria shall be contacted by the local disabled persons' federations by telephone, and written informed consent was obtained from all subjects and their legal guardians. Firstly, all personnel participating in the investigation shall be trained intensively and uniformly, including unifying inquiry standards and inspection methods, and clarifying precautions in the investigation. Then, the blind males were organized and concentrated in the hospital or designated place, and accepted a separate face-to-face questionnaire survey.

Data sorting and analysis 
The questionnaire is uniformly reviewed by the members of the research group and entered into the excel worksheet. The database is established with EpiData 3.1 software and entered by two people.

\section{Result}

Analysis of the general situation of the object

A total of 54 blind males were investigated. The age of the subjects ranged from 19 to 62 years, with a median age of 33.5 years and an average age of $40.57 \pm 9.80$ years. The marital status of 54 blind males, of which married accounted for $66.7 \%$, unmarried accounted for $29.6 \%$, divorced or widowed accounted for $3.7 \%$, and the average age of marriage was $21.45 \pm 11.38$ years. The eye disease $(50.0 \%)$ was most frequent causes of blindness, followed by congenital blindness (18.6\%), trauma (14.8\%), causing by high fever (11.0\%) and unexplained blindness (5.6\%). As shown in Table 1.

Table 1

The general situation of the research object $(n=54)$

\begin{tabular}{|lll|}
\hline & Number (n) & Percentage (\%) \\
\hline Marital status & & \\
\hline Married & 36 & 66.7 \\
\hline Unmarried & 16 & 29.6 \\
\hline Divorced or Widowed & 2 & 3.7 \\
\hline Causes of blindness & & \\
\hline Congenital blindness & 10 & 18.6 \\
\hline Eye disease & 27 & 50.0 \\
\hline High fever & 6 & 11.0 \\
\hline Trauma & 8 & 14.8 \\
\hline Unexplained blindness & 3 & 5.6 \\
\hline
\end{tabular}

Sexual behavior characteristics of the object

Among 54 blind males, according to the international erectile function score (IIEF- 5 score), $70.4 \%$ of blind males had normal erectile function (IIEF-5 score $\geq 22$ ), $16.7 \%$ had mild erectile dysfunction (IIEF-5 score 12-21), 9.3\% had moderate erectile dysfunction (IIEF-5 score $8-11$ ), and $3.6 \%$ had severe erectile dysfunction (IIEF-5 score < 7). The age of first sexual behavior was less than 20 years old $(16.7 \%), 21-25$ years old $(57.4 \%), 26-30$ years old $(11.0 \%)$, and more than 30 years old $(5.6 \%)$, while $9.3 \%$ of blind males had asexual life experience. In terms of sexual frequency, $25.9 \%$ of blind males had sexual behavior 1-4 
times a month, $11.1 \%$ had sexual behavior $4-8$ times a month, $11.1 \%$ had sexual behavior $8-12$ times a month, while $51.9 \%$ of blind males lived asexually in their daily life. About the sexual pleasure, $87.1 \%$ of blind males had sexual pleasure, $3.6 \%$ of blind males had asexual pleasure, and $9.3 \%$ of blind males experienced asexual pleasure because of asexual behavior experience.

The results of 54 questionnaires on access to sexual knowledge showed that the sound of mobile phones (self-media) accounted for $51.9 \%$, radio for $27.8 \%$, the sound of television for $35.2 \%$, and peer communication for $48.1 \%$. The gentle and pleasant voice (64.8\%) was most frequent on understanding of the beauty of sexual partner, followed by sexy and stylish figure (55.5\%), fine and smooth skin $(51.9 \%)$ and attractive body fragrance of the opposite sex (18.5\%). The results on the stimulation of sexual arousal showed that hearing gentle and pleasant sounds accounted for $40.7 \%$, touching delicate and smooth skin for $44.4 \%$, touching sexy and stylish figure for $53.7 \%$, and pleasant mood for $22.2 \%$. As shown in Table 2. 
Table 2

Sexual behavior characteristics of the research object $(n=54)$

\begin{tabular}{|c|c|c|}
\hline & Number (n) & Percentage (\%) \\
\hline \multicolumn{3}{|l|}{ Erectile Function } \\
\hline Normal & 38 & 70.4 \\
\hline Mild erectile dysfunction & 9 & 16.7 \\
\hline Moderate erectile dysfunction & 5 & 9.3 \\
\hline Severe erectile dysfunction & 2 & 3.6 \\
\hline \multicolumn{3}{|l|}{ Age of first sexual behavior } \\
\hline$<20$ years old & 9 & 16.7 \\
\hline $21-25$ years old & 31 & 57.4 \\
\hline $26-30$ years old & 6 & 11.0 \\
\hline$>30$ years old & 3 & 5.6 \\
\hline None & 5 & 9.3 \\
\hline \multicolumn{3}{|l|}{ Sexual frequency } \\
\hline $1-4$ times a month & 14 & 25.9 \\
\hline 4-8 times a month & 6 & 11.1 \\
\hline 8-12 times a month & 6 & 11.1 \\
\hline None & 28 & 51.9 \\
\hline \multicolumn{3}{|l|}{ Sexual pleasure } \\
\hline Sexual pleasure & 47 & 87.1 \\
\hline Asexual pleasure & 2 & 3.6 \\
\hline Asexual behavior experience & 5 & 9.3 \\
\hline \multicolumn{3}{|l|}{ Acquisition of sexual knowledge } \\
\hline The sound of mobile phones (self-media) & 28 & 51.9 \\
\hline Radio & 15 & 27.8 \\
\hline The sound of television & 19 & 35.2 \\
\hline Peer communication & 26 & 48.1 \\
\hline
\end{tabular}




\begin{tabular}{|lll|}
\hline & Number (n) & Percentage (\%) \\
\hline Gentle and pleasant voice & 35 & 64.8 \\
\hline Fine and smooth skin & 28 & 51.9 \\
\hline Sexy and stylish figure & 30 & 55.5 \\
\hline Attractive body fragrance & 10 & 18.5 \\
\hline Sexual arousal & & \\
\hline Hearing gentle and pleasant sounds & 22 & 40.7 \\
\hline Touching delicate and smooth skin & 24 & 44.4 \\
\hline Touching sexy and stylish figure & 29 & 53.7 \\
\hline Pleasant mood & 12 & 22.2 \\
\hline
\end{tabular}

\section{Discussion}

In the study of individual differences in sexual response and the role of sexual fantasy in sexual arousal, people have increasingly recognized the important role of psychological activities in human sexual behavior ${ }^{4}$. Wenxue Li et al. ${ }^{5}$ also proposed that due to the physiological and psychological characteristics of disabled people different from ordinary people, it is generally believed that the sexual problems encountered by disabled people are far more complex than those of healthy people. The problems often involve many aspects such as ethics, morality, physiology, psychology and society. The deaf are often difficult to obtain the most full sexual experience due to their own hearing and speech communication barriers. It is found that the higher the disability level of deaf, the lower the sexual satisfaction. Vision is very important for sexual feeling and behavior. Whether congenital blindness or acquired blindness, lack of sensory impulse from the eyes can affect sexual activities ${ }^{6,7}$. Many scholars have conducted research on sex related diseases for men and women with normal vision, but there is little research on the sexual behavior of the blind ${ }^{1,8,9}$. Therefore, combined with the particularity of blind men, we conducted a survey on the sexual behavior characteristics of the blind, such as the stimulation of sexual arousal, the understanding of sexual partners' beauty and access to sexual knowledge.

The marriage age and the age of first sexual behavior of blind males are generally late, which is closely related to the social environment. Due to physical defects, they are often hindered in finding lover or marriage objects. In the sexual behavior experience, including the age of first experiencing sexual behavior is later than that of normal people, and the frequency of sexual behavior is less, and even some people have no sexual behavior experience. In the experience of sexual behavior, blind people, like normal people, often achieve orgasm and obtain satisfactory sexual pleasure.

Studies support that in daily life, it is generally believed that men respond more strongly to visual sexual stimuli than women, and men are more exposed to all kinds of pornographic networks, magazines, 
newspapers and periodicals than women ${ }^{7}$. With the opening of today's social culture and the tolerance of people's sexual concepts, the sexual behavior of people in various groups in society is not only related to the happiness of individuals and families, but also may affect the stability of the whole society. With the continuous progress of society, the continuous improvement of artificial intelligence, the improvement of the living standards of the blind, all sectors of society including the government also continue to improve their economic status, psychological status, self-care ability. This survey concluded that the blind males' access to sexual knowledge mainly comes from the voice of mobile phone (self-media), radio and television, and peer communication. Unfortunately, there is little or no work on sexual education for the blind in China.

In sexual cognition, the visual sensory organ has become the first important channel for human beings to receive sexual information. Among all sensations, the development of human visual perception is the fastest and most sufficient ${ }^{7}$. After losing sight, the blind have to turn to other senses, including hearing, touch, taste, smell and proprioception, in order to better obtain the information of the surrounding environment. It is generally believed that other senses of the blind may become unusually sharp ${ }^{7}$. This study shows that the blind people's understanding of the sexual partners' beauty is mainly reflected in gentle and pleasant voice, delicate and smooth skin, sexy and stylish figure, heterosexual and attractive body fragrance. From the above results, it can be seen that blind males' understanding of the sexual partners' beauty is mainly reflected in hearing, touch and smell. This is similar to the idea put forward by Wu Jianhui that the blind who lose visual input gradually form their own behavioral ability in line with their own characteristics in their interaction with the surrounding environment ${ }^{10}$. Behind its sensitive hearing and touch, the plasticity of the central nervous system has changed to adapt to the unique sensory world of the blind. It is also consistent with Song Yiqi that the lack of experience of blind students' visual channel leads to the generation of special representation mechanism through tactile channel compensation, which proves that it is consistent with the hypothesis of perceptual symbol theory ${ }^{11}$.

Sexual arousal in normal people is an emotional state produced by the processing of external sexual stimulation, such as visual and auditory sexual stimuli and sexual caress, and internal sexual stimulation, such as sexual fantasy ${ }^{4}$. Sexual arousal consists of physiological, psychological and cognitive components. Physiological sexual arousal includes cardiovascular system, such as changes in heart rate, blood pressure and respiration, and genital response, such as male penile erection and female vaginal congestion. Psychological sexual arousal refers to the emotional and emotional state generated by sexual arousal, while cognitive sexual arousal includes interactive components such as attention, evaluation, classification, motivation and behavioral response to sexual stimulation ${ }^{1,7,9}$. Whether there are differences in sexual psychology and sexual cognition between blind males, especially congenital blind males, and normal people, the stimulating state of sexual arousal should be reflected. Therefore, we conducted a questionnaire survey on the stimulating factors of blind males' sexual arousal, and concluded that the stimulating performance of blind males' sexual arousal was $40.7 \%$ to hear gentle and pleasant sounds, $44.4 \%$ to touch delicate and smooth skin, $53.7 \%$ to touch sexy and stylish body, and 
$22.2 \%$ to feel happy. From the data analysis, it can be seen that the stimulation of blind sexual arousal is mainly reflected in hearing gentle and pleasant sounds, touching delicate and smooth skin, touching sexy and stylish body, but the pleasant mood also has a significant impact. This is also consistent with several studies that put forward that sexual arousal refers to an emotional state generated by an individual when processing external, such as visual and tactile stimulation, or internal such as fantasy $7,12,13$. Similar to other emotions, sexual arousal has obvious antecedent stimulation and expression patterns as the basis for the regulation of sexual reproduction behavior. Sexual arousal consists of physiological changes, emotional expression and motivational behavior.

\section{Conclusion}

To sum up, this study shows that blind males lack formal and systematic sexual education, and their understanding of sexual partner's beauty in sexual behavior mainly includes hearing, touch and smell. The stimulation of sexual arousal is mainly reflected in sound and touch, and pleasant mood also has a certain impact. The number of people investigated in this study is limited, because women have low informed consent rate, and have not been included in the analysis. The contents of the survey need to be further enriched and optimized. The comparison of blind males who are blind before and after the development of congenital blindness or secondary sexual syndrome with normal people or other disabled people with normal vision needs further investigation and analysis.

Due to social status, attention, viability and other problems, the marriage age of blind is generally late, and many even fail to get married. Due to the limited sample size and survey content of this study, only the preliminary analysis of visual, tactile and auditory aspects in sexual arousal has not been carried out in the next step. According to the research proposed by Wan Xing ${ }^{14}$, disabled adolescents are facing a more severe sexual and reproductive health situation than ordinary adolescents, and their own disability makes it difficult for them to obtain equal educational opportunities with ordinary adolescents, lack the ability of self-protection, and have obvious vulnerability to sexual and reproductive health problems. Therefore, it is also hoped that this study can provide more publicity and education on the correct treatment of sexual behavior and paying attention to sexual behavior health for the blind, increase the knowledge of sexual physiology and mental health, and provide help for the better quality of life of blind teenagers and adult friends.

\section{Declarations}

\section{Acknowledgments}

We would like to thank all the volunteers who participated in this study.

\section{Author contributions}

Biao Qian, Jiaguo Huang, Shaoming Huang conceived of the study, and participated in its design and coordination. Shaoming Huang helped to draft the manuscript. Shenghuang Zhu, Renfu Liu, Chuanchuan 
Xiong, Lixin Liu, Shuangshuang Li and Shihan Liu conducted a face-to-face interview survey and questionnaire, and collected data. Shaoming Huang and Jiaguo Huang performed the statistical analysis. All authors read and approved the final manuscript.

\section{Funding}

The financial support from Key Research and Development Program of the Bureau of Science and Technology of Ganzhou, Jiangxi, China (2017-179-89).

\section{Competing interests}

The authors declare no competing interests.

\section{References}

1. Schober, J. M. \& Pfaff, D. The neurophysiology of sexual arousal. Best practice \&amp; research. Clinical endocrinology \&amp; metabolism 21, 445-461 (2007).

2. Juanjuan, F. et al. Etiological analysis of avoidable blindness in visually impaired children. Chinese Journal of Rehabilitation 28, 317-319 (2013).

3. Kun, L. Analysis of identification of visual disability. Chinese Journal of Trauma and Disability Medicine 24, 28-29,30 (2016).

4. Janssen, E. Sexual arousal in men: a review and conceptual analysis. Horm Behav 59, 708-716 (2011).

5. Wenxue, L. et al. Sexual satisfaction and related factors of hearing disabled. National Journal of Andrology 22, 872-876 (2016).

6. Iversen, K. D., Ptito, M., Møller, P. \& Kupers, R. Enhanced chemosensory detection of negative emotions in congenital blindness. Neural Plast 2015, 469750 (2015).

7. Poeppl, T. B., Sakreida, K. \& Eickhoff, S. B. Neural substrates of sexual arousal revisited: Dependent on sex. Proc Natl Acad Sci U S A 117, 11204-11205 (2020).

8. Herz, R. S. \& Cahill, E. D. Differential use of sensory information in sexual behavior as a function of gender. Hum Nat 8, 275-286 (1997).

9. Motofei, I. G. \& Rowland, D. L. The physiological basis of human sexual arousal: neuroendocrine sexual asymmetry. Int J Andro/ 28, 78-87 (2005).

10. Jianhui, W. \& Yuejia, L. Cross sensory channel reorganization in the blind. Advances in Psychological Science 406-412 (2005).

11. Yiqi, S. \& Jijia, Z. Cross channel representation of conceptual features of the blind. Special education in China 41-45 (2012).

12. Panagiotopoulou, E., Filippetti, M. L., Gentsch, A. \& Fotopoulou, A. Dissociable sources of erogeneity in social touch: Imagining and perceiving C-Tactile optimal touch in erogenous zones. PLoS One 13, e0203039 (2018). 
13. Borg, C., Oosterwijk, T. A., Lisy, D., Boesveldt, S. \& de Jong, P. J. The influence of olfactory disgust on (Genital) sexual arousal in men. PLoS One 14, e0213059 (2019).

14. Xing, W. \& Xiaoming, Y. Research Progress on sexual and reproductive health of disabled adolescents at home and abroad. Chinese Journal of Human Sexuality 0, 44-51 (2017). 